\title{
The effect of adding oral oestradiol to progesterone as luteal phase support in ART cycles - a randomized controlled study
}

\author{
Ashraf Moini ${ }^{1,2}$, Shahrzad Zadeh Modarress³, Elham Amirchaghmaghi', Naeimeh Mirghavam ${ }^{1}$, \\ Soraya Khafri ${ }^{4,5}$, Mohammad Reza Akhoond ${ }^{4,6}$, Reza Salman Yazdi ${ }^{7}$
}

\author{
1Endocrinology and Female Infertility Department, Royan Institute for Reproductive \\ Biomedicine, ACECR, Tehran, Iran \\ 2Department of Gynaecology and Obstetrics, Faculty of Medicine, Tehran University \\ of Medical Sciences \& Health Services, Tehran, Iran \\ 32Department of Gynaecology and Obstetrics, Faculty of Medicine, Sahid Beheshti \\ University of Medical Sciences and Health Service, Tehran, Iran \\ 4Epidemiology and Reproductive Health Department, Royan Institute for Reproductive \\ Biomedicine, ACECR, Tehran, Iran \\ ${ }^{5}$ Social Medicine and Health Department, Babol University of Medical Sciences, Babol, \\ Iran \\ 6Statistics Department, Mathematial Science and Computer Faculty, Shahid Chamran \\ University, Ahwaz, Iran \\ ${ }^{7}$ Andrology Department, Royan Institute for Reproductive Biomedicine, ACECR, \\ Tehran, Iran
}

Submitted: 24 January 2010

Accepted: 30 June 2010

Arch Med Sci 2011; 7, 1: 112-116

DOI: $10.5114 /$ aoms.2011.20613

Copyright (c) 2011 Termedia \& Banach

\begin{abstract}
Introduction: Luteal phase support in assisted reproductive technology (ART) cycles is still controversial. The present study was conducted to evaluate the effect of adding oral oestradiol to progesterone during ART cycles.

Material and methods: In this prospective case control study, infertile women under 35 years old who were candidates for IVF/ICSI cycles in Royan Institute were enrolled. A long gonadotropin-releasing hormone $(\mathrm{GnRH})$ agonist protocol was used for ovarian stimulation. Patients were randomly divided into two groups for luteal phase support: the control group received vaginal administration of progesterone supplementation alone starting on the day after oocyte retrieval and continued until the tenth week if the chemical pregnancy test was positive. In the oestradiol group, $2 \mathrm{mg}$ of oestradiol valerate was initiated orally with progesterone. The control group received a placebo instead of oestradiol.

Results: Ninety-eight women were studied as oestradiol $(N=47)$ and control groups $(N=51)$. There were no significant differences in the mean number of retrieved oocytes, number of transferred embryos, or chemical and clinical pregnancy rates between the two groups. Although the serum progesterone concentration was higher in the oestradiol group in comparison to the control group on day 7, 10 and 12 after embryo transfer, these differences were not statistically significant.

Conclusions: The results suggested that adding oral oestradiol to vaginal progesterone supplementation does not improve the chemical and clinical pregnancy rates of IVF/ICSI cycles.
\end{abstract}

Key words: in vitro fertilization (IVF), intracytoplasmic sperm injection (ICSI), oestradiol, luteal phase support (LPS), progesterone.

\author{
Corresponding author: \\ Ashraf Moini MD \\ Endocrinology and Female \\ Infertility Department \\ Royan Institute for Reproductive \\ Biomedicine \\ ACECR, No. 12 \\ Eastern Hafez Street \\ Bani hashem Street \\ Resalat Highway \\ Tehran, Iran \\ P.O. Box: 16635-148 \\ Phone/Fax: +982122510895 \\ E-mail: \\ a_moini@royaninstitute.org
}




\section{Introduction}

Several factors including oocyte quality and receptivity of endometrium influence the success of in vitro fertilization (IVF) cycles [1]. One of these influencing factors is implantation. Implantation of the embryo is critical in determining the success of assisted reproductive technology (ART) because after the transfer of high quality embryos, the pregnancy rate may still be relatively low [2].

Human embryo implantation is a three-stage process involving coordination between a receptive endometrium and a functional blastocyst [3]. Receptivity of the uterus is dependent on the hormonal status of the endometrium at the time of implantation [1]. Oestrogen causes proliferation of endometrial cells in the basal layer and increases progesterone receptors. Progesterone induces secretion from endometrial glandular cells and decidualization of the stromal layer. Therefore adequate concentrations of these hormones are essential for adequate endometrial maturation before embryo implantation [1].

Ovarian stimulation for IVF results in supraphysiological steroid levels and is associated with very low luteinizing hormone (LH) concentrations during the luteal phase [4].

Luteal phase supplementation (LPS), after controlled ovarian stimulation (COS) for IVF, has been a routine practice in IVF - embryo transfer (ET) because stimulated IVF cycles are associated with a defective luteal phase in almost all patients [5, 6]. Although it is generally agreed that LPS in IVF cycles improves the outcome, there is controversy over the best protocol [7]. There is a worldwide controversy concerning the type of hormones used for LPS, its dose and duration, and the time of starting and stopping it [8]. It is well established that luteal support with progesterone improves implantation in ART cycles [9]. Under progesterone supplementation, however, it has been shown that mid-luteal oestradiol (E2) levels decrease in a proportion of patients and that this might be associated with a concomitant decrease in pregnancy rates [10].

There are controversial reports about adding oestrogen to progesterone supplementation as LPS $[1,7,11-13]$. In the present study, the effect of adding oral oestradiol to progesterone for luteal phase support was compared to progesterone alone.

\section{Material and methods}

In this prospective case control study, infertile women under 35 years old who were candidates for IVF/intracytoplasmic sperm injection (ICSI) cycles in Royan Institute were enrolled. This study was approved by the Ethics Committee of Royan Institute and carried out between June 2005 and
December 2007. Exclusion criteria consisted of age > 35 years, polycystic ovary syndrome (PCOs), high grade endometriosis, existence of myoma or adhesion in uterus, E2 level more than 3000 pg/ml on human chorionic gonadotropin (hCG) administration, and body mass index (BMI) more than $29 \mathrm{~kg} / \mathrm{m}^{2}$ or less than $18 \mathrm{~kg} / \mathrm{m}^{2}$. All patients signed an informed consent form.

A long GnRH agonist protocol was used for ovarian stimulation. In this protocol, the women had first been downregulated with a GnRH analogue (Buserlin, Hoechst, Germany) which was administered 0.5 cc subcutaneously from the 21st day of the previous menstrual cycle. When pituitary suppression was achieved (on the second day of the menstrual cycle follicle-stimulating hormone $(\mathrm{FSH}) \leq 5 \mathrm{lU} / \mathrm{ml}$, LH $\leq 5 \mathrm{lU} / \mathrm{ml}$, progesterone $\leq 1 \mathrm{ng} / \mathrm{ml}$, oestradiol $\leq 50 \mathrm{pg} / \mathrm{ml}$ ), its dose was reduced to $0.2 \mathrm{CC}$ and 150-225 IU human menopausal gonadotropin (Menopur, Ferring, Germany) or 150-225 IU recombinant FSH (Gonal-F, Sereno, Italy) was administered intramuscularly from the 2 nd day of the menstrual cycle daily. After 3 or more follicles had reached $17 \mathrm{~mm}$ in diameter, 10000 IU human chorionic gonadotropin (Pregnyl, Daropakhsh, Iran) was used to induce oocyte maturation. Oocytes were aspirated transvaginally with ultrasound guidance 34-36 hours later. Then IVF or ICSI was done. Uterine embryo transfer was performed 48-72 hours after oocyte retrieval. Beta hCG was checked two weeks after embryo transfer. Clinical pregnancy was defined as the presence of at least one gestational sac with detectable fetal heart activity by transvaginal sonography.

For luteal phase support, patients were randomly divided into two groups: group 1 (control) consisted of patients who received vaginal administration of progesterone supplementation $400 \mathrm{mg}$ twice a day starting on the day after oocyte retrieval and continued until the tenth week if the chemical pregnancy test was positive. In the second group (oestradiol group), $2 \mathrm{mg}$ of oestradiol valerate was initiated orally with progesterone. The control group received a placebo instead of oestradiol. In both groups, when the pregnancy test was negative or pregnancy loss occurred, the drugs used for luteal phase support were discontinued. For all hormonal evaluations, venous blood samples of all subjects were collected in Royan Institute's Laboratory at the specified times. Blood samples were allowed to clot; sera were separated by centrifugation and examined immediately or stored at $-20^{\circ} \mathrm{C}$ until assayed. The serum concentration of luteinizing hormone (LH, ELISA, Pishtaz-Teb, Tehran, Iran), oestradiol (E2, ELISA, DRG Instruments GmbH, Marburg, Germany) and progesterone (ELISA, DRG Instruments $\mathrm{GmbH}$, Marburg, Germany) were checked on the hCG administration day and 7, 10 
Ashraf Moini, Shahrzad Zadeh Modarress, Elham Amirchaghmaghi, Naeimeh Mirghavam, Soraya Khafri, Mohammad Reza Akhoond, Reza Salman Yazdi

Table I. Aetiology of infertility among studied groups

\begin{tabular}{|lccc|}
\hline $\begin{array}{l}\text { Cause } \\
\text { of infertility }\end{array}$ & $\begin{array}{c}\text { Oestradiol } \\
\text { group } \\
(N=47)\end{array}$ & $\begin{array}{c}\text { Control } \\
\text { group } \\
(N=51)\end{array}$ & $P$ value \\
\hline Male factor & $32(68.1 \%)$ & $26(51 \%)$ & NS \\
\hline Female factor & $6(12.8 \%)$ & $11(21.5 \%)$ & NS \\
\hline $\begin{array}{l}\text { Male and female } 8(17 \%) \\
\text { factor }\end{array}$ & $13(25.5 \%)$ & NS \\
\hline $\begin{array}{l}\text { Unexplained } \\
\text { factor }\end{array}$ & $1(2.1 \%)$ & $1(2 \%)$ & NS \\
\hline NS - not significant & & & \\
\hline
\end{tabular}

and 12 days after ET. The intra-assay and inter-assay variations (CV\%, min-max) for $\mathrm{LH}$, oestradiol and progesterone were $4.7-6.7 \%$ and $4.0-4.8 \%, 2.71$ $6.81 \%$ and $6.72-9.39 \%, 5.4-6.99 \%$ and $4.34-9.96 \%$, respectively.

\section{Statistical analysis}

The program SAS 9.1 was used for data analysis. Results are presented as mean value \pm standard error (SE). Repeated measure ANOVA, two sample t-test, Fisher's exact test and $\chi^{2}$ test were used for the statistical analysis. $P$ value less than 0.05 was considered significant.

\section{Results}

In this study, 98 women were selected and randomly studied as oestradiol $(N=47)$ and control groups $(N=51)$. The mean age of patients was 30.01 \pm 0.61 in the control group and $30.29 \pm 0.57$ years in the oestradiol group $(P>0.05)$. There were no statistically significant differences between the two groups with respect to cause of infertility (Table I) and type of infertility (primary or secondary).

The mean duration of infertility was $5.98 \pm 0.55$ years in the control group and $7.81 \pm 1.37$ years in the oestradiol group, but this difference was not statistically significant $(P>0.05)$. There were no significant differences between the two groups in $\mathrm{LH}$ levels measured on different days. Although the serum level of progesterone and oestradiol on different days in the oestradiol group was higher than that of the control group, these differences were not statistically significant $(P>0.05)$ (Table II). The mean number of retrieved oocytes, number of transferred embryos, and chemical and clinical pregnancy rate did not significantly differ between the two groups (Table III). In the oestradiol group, among women who had a positive $\beta$ hCG test (25 out of 47), 23 women had an intrauterine gestational sac with detectable fetal heart while one woman had an ectopic pregnancy and in another woman a blighted ovum was detected. All women with positive chemical pregnancy in the control group (19 out of 51) had clinical pregnancy detected by sonography.

\section{Discussion}

Many areas of LPS used in ART cycles remain controversial. One of the subjects of debate in this regard is adding E2 to progesterone. In the present study, the use of oral oestradiol supplementation in combination with vaginal progesterone was evaluated and compared to progesterone alone during ART cycles where a long GnRH agonist protocol was used for controlled ovarian stimulation in all studied women. The results suggested that adding oral E2 did not improve chemical and clinical pregnancy rates.

It is accepted that luteal function is suppressed in IVF cycles using GnRH agonists. This compromised function could potentially be attributed to ovarian stimulation and the resultant altered hormone levels, the process of oocyte retrieval and direct effect of the GnRH agonist on the corpus luteum [14].

Use of GnRH agonists may be associated with decreased production of E2 and progesterone in the luteal phase, a reduction in the length of the luteal

Table II. Comparison of hormonal assays between the two groups

\begin{tabular}{|lccc|}
\hline Hormone assay & $\begin{array}{c}\text { Oestradiol group } \\
(N=47)\end{array}$ & $\begin{array}{c}\text { Control group } \\
(N=51)\end{array}$ & $P$ value \\
\hline Serum oestradiol on hCG day $(\mathrm{pg} / \mathrm{ml})$ & $1021.62 \pm 122.28$ & $1394.22 \pm 86.94$ & $\mathrm{NS}$ \\
\hline Serum oestradiol on day 7 after ET $(\mathrm{pg} / \mathrm{ml})$ & $344.45 \pm 46.07$ & $263.94 \pm 26.45$ & $\mathrm{NS}$ \\
\hline Serum oestradiol on day 10 after ET $(\mathrm{pg} / \mathrm{ml})$ & $303.60 \pm 36.40$ & $209.14 \pm 39.69$ & $\mathrm{NS}$ \\
\hline Serum oestradiol on day 12 after ET $(\mathrm{pg} / \mathrm{ml})$ & $283.94 \pm 35.36$ & $272.18 \pm 58.71$ & $\mathrm{NS}$ \\
\hline Serum progesterone on hCG day $(\mathrm{ng} / \mathrm{ml})$ & $2.73 \pm 1.2$ & $1.13 \pm 0.26$ & $\mathrm{NS}$ \\
\hline Serum progesterone on day 7 after ET $(\mathrm{ng} / \mathrm{ml})$ & $27.85 \pm 3.48$ & $27.29 \pm 1.78$ & $\mathrm{NS}$ \\
\hline Serum progesterone on day 10 after ET $(\mathrm{ng} / \mathrm{ml})$ & $29.17 \pm 1.48$ & $27.38 \pm 2.12$ & $\mathrm{NS}$ \\
\hline Serum progesterone on day 12 after ET $(\mathrm{ng} / \mathrm{ml})$ & $35.21 \pm 3.8$ & $\mathrm{NS}$ & \\
\hline
\end{tabular}

ET - embryo transfer, hCG - human chorionic gonadotropins, NS - not significant 
phase, and impairment of endogenous gonadotropin secretion caused by persistent pituitary suppression [15].

Although there have been different clinical trials studying the effect of adding E2 to progesterone during LPS in ART cycles, these trials were different with regard to the type of oestradiol (oral, transdermal), its dose (2 $\mathrm{mg}$ or $6 \mathrm{mg}$ ), type of COS used (long or short GnRH agonist, GnRH antagonist) and type of progesterone used (intramuscular, vaginal). Some studies showed a positive effect of adding E2 in ART cycles. Farhi et al. studied the effect of adding E2 to progesterone supplementation during the luteal phase in IVF cycles with different $\mathrm{GnRH}$ agonist protocols (short or long). Their results showed that patients who received E2 supplementation and were treated with the long $\mathrm{GnRH}$ analogue protocol had significantly higher pregnancy and implantation rates [11]. In another study, Gorkemli et al. evaluated patients treated with a long ovulation induction protocol in two groups: group I used only $600 \mathrm{mg} /$ day of progesterone vaginally and group II used $100 \mu \mathrm{g} /$ day of transdermal oestradiol in addition to progesterone. They showed that adding oestradiol to progesterone in ICSI-ET cycles may increase implantation and pregnancy rates [12].

Other studies showed no benefits of adding E2. Engmann et al. evaluated the effect of E2 supplementation via the vaginal route on the overall probability of conception in subgroups of patients using the $\mathrm{GnRH}$ agonist suppression, $\mathrm{GnRH}$ antagonist, or microdose $\mathrm{GnRH}$ agonist protocol. Their findings suggested that the use of luteal phase vaginal E2 supplementation does not improve the overall clinical pregnancy rates but may increase the risk of biochemical miscarriage [1]. Serna et al. evaluated the effect of transdermal E2 administered after embryo transfer on cycle outcome. They found no difference between these luteal phase supports [7].

According to these different findings in different trials, in the present study, the serum progesterone and oestradiol levels were measured on different days after ET (7, 10 and 12 days) to compare between the two groups. The results showed that in spite of a mild increase in hormonal levels in the oestradiol group in comparison to the control group, these hormonal differences were not statistically significant. This may be one explanation for the similar pregnancy rate between these two groups in the present study. As we know, one phenomenon in COS is premature luteinization $(\mathrm{PL})$, which is defined as a rise in serum progesterone levels on the day of hCG administration. An increase of absolute progesterone level on the day of hCG administration is considered as premature luteinization in most studies with different cut-off points (from 0.8 to
Table III. Comparison between the two groups in outcome variables

\begin{tabular}{|lccc|}
\hline Variable & $\begin{array}{c}\text { Oestradiol } \\
\text { group } \\
(N=47)\end{array}$ & $\begin{array}{c}\text { Control } \\
\text { group } \\
(N=51)\end{array}$ & P value \\
\hline $\begin{array}{l}\text { Number } \\
\text { of retrieved } \\
\text { oocytes }(n)\end{array}$ & $7.65 \pm 0.68$ & $9.47 \pm 0.67$ & NS \\
\hline $\begin{array}{l}\text { Number } \\
\text { of transferred } \\
\text { embryos }(n)\end{array}$ & $2.91 \pm 0.15$ & $2.78 \pm 0.15$ & NS \\
\hline $\begin{array}{l}\text { Chemical } \\
\text { pregnancy } \\
\text { rate (\%) }\end{array}$ & $53.2 \%(25)$ & $37.3 \%(19)$ & NS \\
\hline $\begin{array}{l}\text { Clinical } \\
\text { pregnancy } \\
\text { rate (\%) }\end{array}$ & $48.9 \%(23)$ & $37.3 \%(19)$ & NS \\
\hline
\end{tabular}

NS - not significant

$2 \mathrm{ng} / \mathrm{ml}$ ) but some authors defined PL as a progesterone/oestradiol ratio of $>1$ [16].

When we considered an increase of absolute progesterone level on the day of hCG administration as $\mathrm{PL}$, this premature rise occurred in the oestradiol group but we did not find an obvious negative effect of it on pregnancy rate. One explanation for this finding is that the consequences of this premature elevation of serum progesterone on IVF outcome remain controversial [16]. Also it seems that using the level of a single sex hormone on the hCG administration day to predict pregnancy outcome in patients undergoing IVF is confounding [17]. In addition, we observed this $\mathrm{PL}$ in the group which was treated with oestradiol supplementation. It seems that oestradiol may affect the occurrence of $\mathrm{PL}$. As Elnashar mentioned in his article, several mechanisms are considered to explain the PL, such as elevation of follicular LH levels, serum accumulation of hCG from HMG, increased LH receptor sensitivity of the granulosa cells to $\mathrm{FSH}$ or poor ovarian response with increased LH sensitivity [16], but none of them could completely explain this phenomenon. One of these mechanisms which may explain $\mathrm{PL}$ in the oestradiol group in the present study is increased $\mathrm{LH}$ receptor sensitivity of the granulosa cells to $\mathrm{FSH}$, because it is suggested that the increased LH receptor sensitivity in the granulosa cells is due to higher cumulative exposure to oestradiol, which, in conjunction with $\mathrm{FSH}$, could be one of the mechanisms to account for the premature increases in serum progesterone concentration [16]. Nevertheless, we could not draw any conclusion in this regard.

Although adding oestradiol is a subject of debate in LPS, another controversy concerns the dose of oestradiol. Lukaszuk et al. in their prospective 
clinical trial evaluated the influence of different E2 supplementation doses ( 2 and 6 mg daily) during the luteal phase on implantation and pregnancy rates in women undergoing ICSI cycle. In their findings, significantly higher implantation rate and pregnancy rate were found in patients who received low dose E2 supplementation compared with no E2 supplementation, but the best outcomes were found significantly in the group with high dose E2 supplementation. They suggested that for women undergoing a long GnRH analogue protocol, addition of a high dose of E2 to daily progesterone supplementation significantly improves the IVF-ET outcomes [18].

Different doses of oestradiol were not compared in the present study and this may be one of its limitations. Another limitation of the present study is its relatively low sample size because it was necessary to take blood samples at least 5 times during the study and some patients did not consent to that.

In conclusion, the present study showed that the addition of oral oestradiol with a dose of $2 \mathrm{mg}$ daily to vaginal progesterone supplementation as luteal phase support did not improve chemical and clinical pregnancy rates of IVF/ICSI cycles. Further studies with a larger sample size and using different doses of oestradiol are recommended.

\section{Acknowledgment}

The authors wish to thank the physicians and scientific staff of Royan Institute for their cooperation.

\section{References}

1. Engmann L, DiLuigi A, Schmidt D, Benadiva C, Maier D, Nulsen J. The effect of luteal phase vaginal estradiol supplementation on the success of in vitro fertilization treatment: a prospective randomized study. Fertil Steril 2008; 89: 554-61.

2. Valbuena D, Jasper M, Remohí J, Pellicer A, Simón C. Ovarian stimulation and endometrial receptivity. Hum Reprod 1999; 14: 107-11.

3. Achache $\mathrm{H}$, Revel A. Endometrial receptivity markers, the journey to successful embryo implantation. Hum Reprod Update 2006; 12: 731-46.

4. Tavaniotou A, Albano C, Smitz J, Devroey P. Comparison of $\mathrm{LH}$ concentrations in the early and mid-luteal phase in IVF cycles after treatment with HMG alone or in association with the $\mathrm{GnRH}$ antagonist Cetrorelix. Hum Reprod 2001; 16: 663-7.

5. Kolibianakis EM, Devroey P. The luteal phase after ovarian stimulation. Reprod Biomed Online 2002; 5: 26-35.

6. Pabuccu R, Akar ME. Luteal phase support in assisted reproductive technology. Curr Opin Obstet Gynecol 2005; 17: 277-81.

7. Serna J, Cholquevilque J, Cela V, Martínez-Salazar J, Requena A, Garcia-Velasco JA. Estradiol supplementation during the luteal phase of IVF-ICSI patients: a randomized, controlled trial. Fertil Steril 2008; 90: 2190-5.

8. Aboulghar M. Luteal support in reproduction: when, what and how? Curr Opin Obstet Gynecol 2009; 21: 279-84.

9. Pritts EA, Atwood AK. Luteal phase support in infertility treatment: a meta-analysis of the randomized trials. Hum Reprod 2002; 17: 2287-99.

10. Sharara FI, McClamrock HD. Ratio of oestradiol concentration on the day of human chorionic gonadotrophin administration to mid-luteal oestradiol concentration is predictive of in-vitro fertilization outcome. Hum Reprod 1999; 14: 2777-82.

11. Farhi J, Weissman A, Steinfeld Z, Shorer M, Nahum H, Levran D. Estradiol supplementation during the luteal phase may improve the pregnancy rate in patients undergoing in vitro fertilization - embryo transfer cycles. Fertil Steril 2000; 73: 761-6.

12. Gorkemli H, Ak D, Akyurek C, Aktan M, Duman S. Comparison of pregnancy outcomes of progesterone or progesterone + estradiol for luteal phase support in ICSIET cycles. Gynecol Obstet Invest 2004; 58: 140-4.

13. Gleicher N, Brown T, Dudkiewicz A, et al. Estradiol/progesterone substitution in the luteal phase improves pregnancy rates in stimulated cycles-but only in younger women. Early Pregnancy 2000; 4: 64-73.

14. Fauser BC, Devroey P. Reproductive biology and IVF: ovarian stimulation and luteal phase consequences. Trends Endocrinol Metab 2003; 14: 236-42.

15. Jee BC, Suh CS, Kim SH, Kim YB, Moon SY. Effects of estradiol supplementation during the luteal phase of in vitro fertilization cycles: a meta-analysis. Fertil Steril 2010; 93: 428-36.

16. Elnashar AM .Progesterone rise on the day of HCG administration (premature luteinization) in IVF: an overdue update. J Assist Reprod Genet 2010; 27: 149-55.

17. Lee FK, Lai TH, Lin TK, Horng SG, Chen SC. Relationship of progesterone/estradiol ratio on day of hCG administration and pregnancy outcomes in high responders undergoing in vitro fertilization. Fertil Steril 2009; 92: 1284-9.

18. Lukaszuk K, Liss J, Lukaszuk M, Maj B. Optimization of estradiol supplementation during the luteal phase improves the pregnancy rate in women undergoing in vitro fertilization-embryo transfer cycles. Fertil Steril 2005; 83: $1372-6$ 